\title{
Examining Urbanization and the Increasing Challenge of Urban Flood Disaster Risk in Nigeria
}

\author{
Bakare GO* \\ Department of Urban and Regional Planning, Faculty of Environmental Studies, \\ Nigeria
}

*Corresponding author: Bakare Ganiyu Olalekan, Department of Urban and Regional Planning, Faculty of Environmental Studies, Rufus Giwa Polytechnic, PMB 1019, Owo, Ondo State, Nigeria, E-mail: gbakare@rugipo.edu.ng

\section{Review Article \\ Volume 1 Issue 3}

Received Date: October 16, 2017

Published Date: October 27, 2017

DOI: $10.23880 /$ jenr- 16000113

\section{Abstract}

Urbanization as one of the demographic features in the world comes with lots of challenges and associated risks, one of which is flood disaster risk, while flood disaster is starring most cities of the world in its face, flood disaster is not entirely the cause(s) of both human and material resources loss, but rather the levels of vulnerability and exposure of people, elements and environment to potential disaster. In Nigeria therefore a number of flood disaster events have been recorded and which were reviewed in this study. The paper made use of both secondary quantitative and qualitative data, to examine cities situations as regards flood disaster, also an extensive literature review on urbanization and flood disaster risk conceptual issues were carried out. The paper critically looked at the growing challenges and risks posed by flood disaster risk across the world with particular concentration on Nigeria scenarios between 1985 and 2016. The reviewed data revealed that, a huge numbers of lives have been lost, and also material properties worth billions of Naira have also been lost to flood disaster, hence, the identified huge gap in addressing flood disaster risk by concerned stakeholders is advance in this paper, while some coordinated efforts and concerted strategies to reduces the growing challenge of urban flooding in Nigeria were recommended, among which are the issue of policy formulation, designing of emergency strategy planning and spatial redevelopment in most of Nigeria cities, as measures to stem the tide or the growing trends of urban flood disaster in Nigerian cities.

Keywords: Flood Disaster Risk; Urbanization and Urban Flooding; Disaster Risk Management Vulnerability and Exposure 


\section{Journal of Ecology \& Natural Resources}

\section{Background to the Study}

Urbanization involves continue growth of urban centre, which involves spatial growth of the city and also the increase in population concentration in the city. Available data have shown that, the major cities of the world is growing at an alarming rate, while, urbanization is fast impacting its negative consequences on most of the cities as a result of rapid urban development/land use change in the form of massive road/building construction, removal of soil surface for infrastructure purposes, drainage/canal construction, clearance of forest, soil surface pavement and vegetation, has all increased the runoff to stream from rainfall and snowmelt, thereby increases the risk of flooding in the cities around the world, some of the cities are; London, New York, Tokyo and Ontario [1,2]. By 2030, the majority of Africa's population is projected to live in urban areas, unfortunately, global warming, which is not majorly caused by African continent, is also bringing chronic flooding to the African cities, which can be as disastrous for the poor and the rich alike, such cases are found in Nairobi-Kenya, Accra-Ghana, Kampala-Uganda and Maputo-Mozambique [3]. Also, 'urbanization as the defining feature of the world demographic growth, is implicated in and compound flood risk, while in 2008 for the first time in human history, half of the world's population lived in urban areas with two third of this in low-income and middle-income nations. This is estimated to rise to 60 percent in 2030 and 70 percent in 2050, to a total of 6.5 billion, or double the projected rural population for that time. As urban population comes to represent the larger proportion of the world population, then, urban floods will account for an increasing part of total flood impact' [4], hence the urgent need to explore the issues surrounding flood disaster risk in the context of the growing losses and damages as a result floods disaster around the world cannot be over-emphasized.

Urbanization as a process, has become the defining feature of the world's demographic growth, with the populations of cities, towns and villages swelling, especially in developing countries, where floods are affecting and devastating more urban areas, and unplanned development in floodplains, ageing drainage infrastructure, increased paving of soil surface and other impermeable surfaces, with lack of flood risk reduction activities, all contribute to flood disaster impacts [4]. As many cities of the world, especially in developing nations, like Nigeria is currently experiencing rapid economic and population growth, due to urbanization process, i.e the transition from rural to largely urban societies, put. As a result of this huge proportion people, and assets are put at risk, with no measures and strategies in place to handle the challenges that comes with flood disaster, which eventually leads to larger parts of the cities being vulnerable to flood disaster risk.

\section{Urbanization and Urban Floods}

Understanding the concepts of urbanization and urban floods, comes with so many challenges, because urbanization comes with increasingly larger scale urban spatial expansion, as cities and towns swell and grow outwards in order to accommodate population increases, this expansion alters the natural landscape, land uses and land cover processes, thereby changing water flows and increasing impermeable areas and complicates flood hazard problem [5]. Hence, the consequent increases in urban populations, accompanied by urban expansion, can result in decline of average densities, as built-up areas spread outwards, this can complicate flood risk and weaken urban resilience to flooding [6]. However, in Nigeria like in other countries of the world, flood disaster risks in cities arises from both the natural and man-made sources, though, the growing challenge of urban flood cannot be handled without understanding the issues of rapid urban growth and corresponding infrastructural provision that can handle flood outbreak.

The occurrence of floods happens to be the most frequent of natural disasters occurring in the cities, causing tremendous losses and social disruptions worldwide [7,4]. Flood affect urban settlement of all types, from small villages and mid-sized market town and service centers, examples are; Indus River, to major cities, megacities and metropolitan areas such as, Sendai, Brisbane, New York, Karachi and Bangkok, Nairobi, Freetown, and Accra. Meanwhile, in Nigeria flood disaster has been recorded in Lagos to Port-Harcourt, from Kano to Asaba, from Suleja to Yenegoa, from Sokoto to Makurdi, from Lokoja to Ibadan etc. all these towns have experienced one form of destructive/deadly floods or the other since 2010 till date (Table 2). Studies reviewed, define flood as a combination of meteorological and hydrological extremes, such as extreme precipitation and flows, which can also occur as a result of human activities: flooding of property and land can be a result of unplanned growth and development in floodplains, or from breach of a dam or the overtopping of an embankment that fails to protect planned developments, while urban flooding causes damage to buildings, utility works, housing, household assets, income losses in industries and trade, loss of employment to daily earners or temporary workers and interruption to transport systems [4]. 


\section{Journal of Ecology \& Natural Resources}

\begin{tabular}{|c|c|c|c|c|}
\hline \multicolumn{5}{|c|}{ Population (in millions) } \\
\hline Region & 2017 & 2030 & 2050 & 2100 \\
\hline World & 7550 & 8551 & 9772 & 11184 \\
\hline Africa & 1256 & 1704 & 2528 & 4468 \\
\hline Asia & 4504 & 4947 & 5257 & 4780 \\
\hline Europe & 742 & 739 & 716 & 653 \\
\hline $\begin{array}{c}\text { Latin America and the } \\
\text { Caribbean }\end{array}$ & 646 & 718 & 780 & 712 \\
\hline Northern America & 361 & 395 & 435 & 499 \\
\hline Oceania & 41 & 48 & 57 & 72 \\
\hline
\end{tabular}

Source: United Nations, Department of Economic and Social Affairs, Population Division (2017)

World Population Prospects: The 2017 Revision. New York

Table 1: Population of the World and Regions for the year 2017, 2030, 2050 and 2100, According to MediumVariant Projection.

Table 1 indicates that global population will continue to grow in an unprecedented manner. The issue of rapid urbanization contributed in no small means to the incessant flood disaster risk in major cities of the world. Records showed that, the world's population numbered nearly 7.6 billion as of mid-2017 (Table 1), today, the world's population continues to grow, while, the global population was growing by 1.2 percent/per year, today it is growing by 1.10 percent/per year, yielding an additional 83 million people annually. Therefore, the world's population is projected to increase by slightly more than 1 billion people over the next 13 years, reaching 8.6 billion in 2030 and to increase further to 9.8 billion in 2050 and 11.2 billion by 2100 (see Table 1). However, more than half of the anticipated growth in global population between 2017 and 2050 is expected to occur in Africa, with additional 2.2 billion people to be added between 2017 and 2050 is projected to be 1.3 billion and of these population growth to be from Africa, Nigeria occupies a very large chunk of the projected people [8]. Hence this call for a serious concerned and coordinated actions and plans to forestall any complexities that may likely arose as a result of this growth.

Globally, more people live in urban areas than in rural areas, with $54 \%$ of the world's population residing in urban areas in 2014, and by $2050,60 \%$ of the world's population is projected to be urban, while continuing population growth and urbanization are projected to add to the world's population by 2050 , with nearly $90 \%$ of the increase concentrated in Asia and Africa. Between 2014 and $2050,90 \%$ of the expected increase in the world's urban population will take place in the urban areas of
Africa and Asia [9], just three countries India, China and Nigeria are expected to account for $37 \%$ of the projected growth of the world's urban population between 2014 and 2050, where India is projected to add 404 million urban dwellers, China 292 million and Nigeria 212 million. This assertion will significantly affect the spatial spread of cities in Nigeria and also stand them at vulnerable positions to flood disaster event or occurrence, hence there is great need to properly understand likely risk posed by flood disaster and how best such can be tackled.

\section{Floods and Urban Flooding}

There is a growing need to revisit floods and urban flood risk knowledge with particular focus on understanding the interaction between urban development (urbanization) and urban risks, one of which is prominent among these risks is flood [10], and its major negative impacts on cities, while this type of flood is often referred to as urban flooding. It was found out that, floods are already having sever impacts on cities, and smaller urban centres, with an increasing urbanizing world, flood disaster are reportedly increasing and particularly impacting the poor negatively $[11,12]$. Since floods as one of the most frequent and widespread of all environmental hazards of various types and magnitudes, occur in most terrestrial portions of the globe, causing huge human and animal losses in terms of damage and disruption to economic livelihoods, businesses, infrastructure, services and public health, while long term data suggest that, floods and wind-storms (which frequently lead to flooding) have been by far the most common causes of natural disaster worldwide over the past 100 years [13].

Nigerian as a fast growing country with huge numbers of her populations in major cities come along with many challenges and prospects, some of the challenges includes but not limited to floods and flood disaster risk. Urbanization on its own aggravate flooding by restricting where flood can go, covering large parts of the ground with roofs, roads and pavements, obstructing sections of natural channels and building drains that ensure that water moves to rivers faster than it did under natural conditions. As more people crowd into cities, the effects of huge population in the cities intensify, and as a result, even quite moderate storms produce high flows in rivers because there are more hard surfaces and drains [3]. As mentioned earlier, the occurrence of floods is the most frequent among all natural disasters [4], caused by river overflows, flash floods, in the cities, and coastal floods in the coastal areas in the past twenty years in particular, it 
affects more people globally than any other type of natural disaster, the number of reported flood events has been increasing significantly $[14,15]$ (Table 2).

Also, is observed that, when flood waters physically encroach on people and infrastructure, the vulnerability of people and infrastructure is decisive for the degree of harm and damage. The impact on urban centres are much in terms of economic loss both directly or indirectly because of high population density (urbanization), large impervious areas, clogging of drainage/non-desilting of drains and canal systems, high economic values of properties and infrastructure among others [16]. In the past twenty years in particular as stated earlier, the number of reported flood events has been increasing significantly, the numbers of people affected by floods, the financial economic and insured damages have all increased too. In 2010 alone, 178 million people were affected by floods. The total losses in exceptional years such as 1998 and 2010 exceeded $\$ 40$ billion, it also recorded highest number of deaths among all other natural disaster, with 8,633 deaths, followed by storms with 8,344 and earthquakes with 1,095 deaths among others [17,4]. The impact of urban floods are also distinctive, given the traditionally higher concentration of population and asset, this makes damage more intense and more costly, urban settlement also contains the major economic and social attributes and asset bases of any national population, hence urban flooding by causing damage and disruptions beyond the scope of the actual floodwaters often carries more serious consequences for society $[4,16]$. In some of Nigerian cities, there exist clustered of people, properties and infrastructure in the city centres, which in most cases increases the number of losses often suffered during an outbreak of flood disaster.

\section{Conceptual Issues and Literature Review in Flood Disaster Risk}

Disaster and disaster risk (from disaster, to risk): Disaster often times than not are sometimes considered external shocks, but disaster risk results from the complex interaction between development process that generate conditions of exposure, vulnerability and hazard, it is also considered as the combination of the severity and frequency of a hazard, the numbers of people and assets exposed to the hazard, and their vulnerability to damage $[18,19]$. Disaster is also seen as severe alterations in the normal functioning of a community or a society due to hazardous physical events interacting with vulnerable social conditions, leading to widespread adverse human, material, economic, or environmental effects that require immediate emergency response to satisfy critical human needs and that may require external support for recovery
[16], some of these conditions are related to issues of employment opportunities, poverty, accessibility to land and accommodation, topography etc. On the other hand, hazard that is closely related to disaster is viewed as a source of potential harm, a situation with the potential to cause damage or a threat/condition with the potential to create loss of lives or to initiate a failure to the natural, modified or human systems [21]. The keyword here is the word exposure and vulnerability, people, elements and society has to be exposed firstly, and vulnerability to flood disaster risk for losses in terms of deaths, economic loss and agricultural losses to be recorded, hence, people, elements and society must be protected from these two issues for effective flood disaster risk management to be achieved.

Conceptualizing, disasters in this regard are not limited to, floods, drought, earthquake, volcanic eruption, snow avalanche, tropical cyclones etc but occurrence of disaster is always preceded by the existences of specific physical and social conditions that are generally referred to as disaster risk, [22-29]. These physical and social conditions are simply conditions that make people vulnerable to disaster risk, and make people easily fallible to disaster. Disaster risk derived from a combination of physical hazards and the vulnerabilities of exposed elements will signify the potential for severe interruption of the normal functioning of the affected society once it materializes as disaster [20]. The point here is that, disaster hardly can impact massive negative consequences on elements/people around where it occurs, if the combinations of certain social, economic and environmental vulnerabilities factors are not present to make such location a disaster risk area or make the element/people living in such location vulnerable to disaster risk.

It therefore can be explained that, the term element at risk includes all elements of human system, such as the built environment and the natural environment that are at risk of flooding in a given area, example of which are the population, buildings and civil engineering worksroad construction, drainage construction, bridge construction, surface pavement, economic activities, ecosystems, etc., will experience adverse consequences like fatalities, injuries or psychological stress, destruction of buildings, properties, interruption of traffic flow or business, pollution of soil /environment [30]. While flood disaster risk is explained in terms of risk to human society, and is seen as a product of the severity and probability of occurrence of flood disaster and the vulnerability of the population system [31]. It is also seen as, the possibility that floods of a given magnitude and a given loss will occur 
within a given time span, it is a function of hazard, exposure, and vulnerability [27;7]. Examples of which properties worth billions of Naira in Nigeria were lost, houses submerged, lives were lost and agricultural produce were either lost or destroyed in virtually every regions of Nigeria. Therefore for a village, town, or city to be flood disaster risk prone, it has to be exposed to certain physical, social economical and environmental barriers/factors, hence this makes the people vulnerable to flood disaster risk. However, the extent of flood damage is dependent of the severity, intensity of the flood and ultimately on the level(s) of vulnerability of the affected elements at risk.

\section{Vulnerability to Disaster Risk (disaster risk to vulnerability)}

In a broader sense, the losses and impacts that characterize disasters usually have much to do with exposure and Vulnerability of people, elements and environment/places, as they do with the severity of hazard/disaster event (UNISR). The concept of vulnerability is referred to in disaster risk to include but not limited to characteristics of a person or group, or element and their situation that influences their capacity to anticipate, cope with resistance and also be able to recover from possible adverse effects of physical disastrous event(s), it is the propensity or predisposition to be adversely affected by disaster, such predisposition constitutes an internal characteristics of the affected person(s), element or group $[25,20]$. People, element, or group of persons and environment can be vulnerable to disaster risk as a result of his socio-economic (social, economic) background, location (topography, terrain) of accommodation, political lineage or ideology, or cultural (ethnicity, race) background, institutional, natural resources, and environmental conditions and processes. Vulnerability is divided into physical and socioeconomic aspects [20,32]. It is also argued that, analysis of vulnerability increasingly highlights its socially constructed nature, underlining the importance of understanding how socio-political process can create vulnerability and thereby result into disaster [33,34]. Therefore, vulnerability to flood disaster risk indicate the inability of society, persons or group of people or elements to cope with certain characteristics and circumstances in form of (socioeconomic conditions, physical conditions and environmental conditions) which invariably makes the society to be susceptible to the damaging and destructive effects of flood disaster risk. Although physical vulnerability is strongly linked to exposure, while efforts to quantify socioeconomic vulnerability are extremely limited, and information of this kind is rarely integrated into risk assessment [35]. It was recorded on exceptions that, socioeconomic vulnerability has links with incidence of malnutrition within affected community through geospatial surveys [36].

\section{Exposure to Disaster Risk}

For proper understanding of disaster risk, exposure is one of the most critical concepts that has to be fully understood, exposure is employed here to refer to the presence of people, livelihoods, environmental services and resources, infrastructure, or economic, social, or cultural assets in places that could be adversely affected by physical events and which thereby, are subject to potential future harm, loss, or damage [20]. However, high vulnerability and exposure are generally the outcome of skewed development processes in most of urban centres, such as those associated with environmental mismanagement, demographic changes, rapid and unplanned urbanization in hazardous areas, failed good governance, and the scarcity of livelihood options for the poor [18]. In flood disaster risk, exposure analysis answers the question "who or what will be affected by floods?" some of which includes, the economic resources/activities, buildings, human lives etc, exposure can therefore be quantified by a number or the value of elements at flood risk [30]. Assessing flood disaster risk without detailed evaluation of elements under the threat of risk as earlier mentioned may not produced the required outcome, but a detailed mapping of the element under the risk of flooding must be delineated for necessary action(s) so as to reduce the level of vulnerability and exposure.

\section{Disaster Risk Management}

Disaster risk management, as a concept is referred to as the reaction on an event, which is indicated by responses and recovery phases of disaster occurrence, the concepts used in the processes for designing, implementing and evaluating strategies, policies and measures to improve the understanding of disaster risk, to foster disaster risk reduction and transfer; promote continuous improvement in disaster preparedness, response, and recovery practices, with the explicit purpose of increasing human security, well-being, quality of life, and sustainable development [20]. Between 1960s and 1980s, the principal means of mitigating the impacts of floods remained physical flood control measures (via the construction of levees, dykes, diversion channels, dam and related structures). However, as population and urbanization continue to increase, flood plains were developed, flood losses continued to also increase, and the need to do things differently became more obvious [37]. 


\section{Journal of Ecology \& Natural Resources}

But recent development in respect to flood disaster risk management is now proofing the physical flood control to be ineffective.

On the other hand, flood disaster response and recovery needs preparation which is supported by the flood risk management, these two areas of flood disaster risk management is key to achieved optimal results in reducing the number(s) of deaths, number of people affected one way or the other, and also the economic loss/damage that may result from flood disaster.

\begin{tabular}{|c|c|c|c|c|c|c|}
\hline $\mathbf{S} / \mathbf{N}$ & $\begin{array}{l}\text { Disaster } \\
\text { Number }\end{array}$ & Disaster Type & Disaster Date & Total Deaths & Total Affected & $\begin{array}{l}\text { Total Economic } \\
\text { Damage (in'000 } \\
\text { US\$) }\end{array}$ \\
\hline 1 & $1985-0015$ & Flood & 23-09-1985 & NA & N A & 8000 \\
\hline 2 & $1988-0334$ & Flood & ??-08-1988 & N A & 300000 & N A \\
\hline 3 & $1994-0208$ & Flood & \#\#\#\#\#\#\# & $\mathrm{NA}$ & 580000 & 66500 \\
\hline 4 & $1998-0308$ & Flood & \#\#\#\#\#\#\# & NA & 100000 & N A \\
\hline 5 & $1999-0370$ & Flood & 15-09-1999 & $\mathrm{NA}$ & 90000 & N A \\
\hline 6 & $2000-0620$ & Flood & $20-09-2000$ & $\mathrm{NA}$ & $\mathrm{NA}$ & 4805 \\
\hline 7 & $2001-0494$ & Flood & $27-08-2001$ & $\mathrm{NA}$ & $\mathrm{NA}$ & 3000 \\
\hline 8 & $2003-0455$ & Flood & $5 / 9 / 2003$ & $\mathrm{NA}$ & 210000 & 2570 \\
\hline 9 & $2009-0375$ & Flood & \#\#\#\#\#\#\# & $\mathrm{NA}$ & 150000 & $\mathrm{NA}$ \\
\hline 10 & $2010-0509$ & Flood & 13-09-2010 & 40 & 1500200 & 30000 \\
\hline 11 & $2011-0230$ & Flood & 21-06-2011 & $\mathrm{NA}$ & N A & 4500 \\
\hline 12 & $2011-0214$ & Flood & $15-07-2011$ & $\mathrm{NA}$ & 26965 & $\mathrm{NA}$ \\
\hline 13 & $2011-0343$ & Flood & $26-08-2011$ & 120 & N A & N A \\
\hline 14 & $2012-0366$ & Flood & $1 / 7 / 2012$ & 363 & 7000867 & 500000 \\
\hline 15 & $2013-0386$ & Flood & 14-04-2013 & $\mathrm{NA}$ & 81506 & N A \\
\hline 16 & $2015-0448$ & Flood & $5 / 9 / 2015$ & 53 & 100420 & 25000 \\
\hline 17 & $2016-0337$ & Flood & $1 / 9 / 2016$ & $\mathrm{NA}$ & 12000 & $\mathrm{NA}$ \\
\hline \multicolumn{4}{|c|}{ Total } & 576 & $\begin{array}{c}\text { 10,151,958 } \\
\text { Persons }\end{array}$ & US\$ $644,375,000$ \\
\hline
\end{tabular}

Source: Adapted and Modified from EM-DAT-CRED, 2017

Table 2: Summary of Flood Disaster Profile in Nigeria between 1985-2016.

Table 2 indicates the available records/data on flood disaster between a period of 1985 to 2016 in Nigeria. It presents a total death rate of 576 people, while a total of $10,151,958$ persons were affected one way or the other, and a total estimate sum of US\$ 644,375,000 were recorded as the total economic damage or destruction due to flood disaster. Although, the record/estimate in table 2 does not take into considerations the data/records of the years where records/data were unknown or unavailable, this is because records of these events were not taken. The data in table 2 calls for a concerted efforts in flood disaster because this data shows a growing trends in both human and material loss to flood disaster in Nigeria since 1985 till date [38].

\section{Findings from the Study}

The continuous increase in the world population, especially the projected population of the cities in developing countries of the world is a call for actions, where there is no corresponding provisions of infrastructure to match the continue increase in human growth.

Table 3 revealed that the death rate recorded as a result of flood disaster in Nigerian cities between 2012 to mid August 2017 to be above 199 people, a total estimate of above 1,094,600 homeless persons were reported, a total number of 44 persons were reported to be missing, while a total estimate of 8,368 homes, churches, shops, bridges, schools, healthcare/hospitals were, destroyed, damaged or submerged by flood disaster during the periods of five years under investigation.

The issue of emergency and response mechanism were not recorded from available date, this clearly showed that, Nigeria emergence response still remained poorly coordinated, If the trends of flood disaster events in Nigerian cities are not arrested, the loss recorded shall continue on a growing trend. 


\section{Journal of Ecology \& Natural Resources}

\section{Recommendations}

Therefore, strategic and concerted efforts has to be made collectively by all the stakeholders to ensure the growing trends of flood disaster is halted, and this can be achieved, if the following recommendations are considered by all;

A. Going through the data and concepts reviewed, the current levels of flood impacts give urgency to the need to make flood disaster risk in urban settlements a high priority on the political discuss and decisions and policy agenda of Nigeria Government at Local, State and National levels.

B. Also, understanding the various concepts of flood disaster risk, its causes and effects, designing, investing in and implementing measures, strategies, which minimizes the risk, must become parts of mainstreaming these into the three tiers of Government at Local, State and National levels to encourage sustainable urban development.

C. It is obvious that government alone cannot tackle the challenges posed by flood disaster alone, hence all appropriate action should be taken to create legal, administrative and economic frameworks that allows private and voluntary organizations to make their contributions to effective flood disaster management.

D. Preparation of information policy statement that encompasses communication/early warning system and facilitates public participation in decision-making should be made available to citizens by the three tiers of governments in Nigeria.

E. Effective spatial redevelopment planning should be carried out where necessary, where building codes and land use control is effectively considered, since most physical developments in cities are as a result of rapid urbanization and land use/land cover change.

F. Effective and coordinated emergency planning and management should be put in place to forestall flood disaster and eventually reduce damages that may likely occur as a result of flood disaster [39,40].

\section{Conclusion}

It is clear from the reviewed literature, conceptual issues and available flood disaster records/data, that the challenge of flood disaster is huge but, if there is coordinated efforts from the public, city dwellers, government, Non Government Organizations, Faith Based Organizations and International Organizations, the growing challenges posed by flood disaster can be reduced, and this can be achieved, if recommended suggestions can be implemented.

\section{References}

1. USGS (United States Geological Survey) (2011) The 1972 black hills rapid city flood revisited, place USGS.

2. Nirupama N, Simonovic SP (2006) Increase of flood risk due to urbanization: A Canadian example. Natural Hazard 40: 25-41.

3. Action Aid (2006) Climate change, urban flooding and the rights of the urban poor in Africa.

4. Jha AK, Robin B, Jessica L (2012) Cities and Flooding: A guide to integrated urban flood risk management for the $21^{\text {st }}$ century. World Bank.

5. Satterthwaite D (2011) How urban societies can adapt to resource shortage and climate change. Phil Trans R Soc A 369: 1762-1783.

6. World Bank (2008) Climate resilient cities: a primer reducing vulnerabilities to climate change impact and strengthening disaster risk management in East Asia cities: Washington DC: World Bank, FGDRR and UNISDR.

7. Vanneuville W, Kellens W, DeMaeyer P, Reniers G, Witlox F (2011) Flood risk management vs. flood disaster management.

8. United Nations, Department of Economic and Social Affairs, Population Division, (2017) World Population Prospects: The 2017 Revision, Key Findings and Advance Tables. Working Paper No. ESA/P/WP/248.

9. United Nations, Department of Economic and Social Affairs, Population Division, (2014) World Urbanization Prospects: The 2014 Revision Highlights.

10. Benjamin MA (2007) Analysing urban flood risk in low cost settlement of Geoge Western Cape, South Africa: Investigating physical and social dimension, a thesis submitted to the University of Cape Town, in fulfillment of the requirement for the degree of Masters in Social Science Department of Environmental and Geographical Science, University of Cape Town.

11. Huq S, Kovats S, Reid H, Satterthwaitte D (2007) Editorial: Reducing risks to cities from disasters and climate change. Environment and Urbanisation 19 (1): 3-15. 
12. Alam K, Herson M, O’Donnel I (2008) Flood and Disaster: Learning from previous relief and recovery operations. Prevention Consortium and ALNAP.

13. Few R, Ahern M, Matnias F, Kovats S (2004) Flood, health and climate change: A strategic review. Working paper No. 63 Tyndall Centre for Climate Change Research.

14. Tsakiris G (2014) Flood risk assessment: concepts, modeling, applications. J Natural Hazards and Earth System Sciences 14: 1361-1369.

15. McCallum I, Liu W, See L, Mechler R, Keating A, et al. (2016) Technologies to support community flood disaster risk reduction. In International Journal of Disaster Risk Science 7(2): 198-204.

16. Tingsanchali $\mathrm{T}$ (2012) Urban flood disaster management. Procedia Engineering 32: 25-37.

17. Swiss Re, Sigma (2014) Global Catastrophes in 2013.

18. Cardona OD, van Aalst MK, Birkmann J, Fordham M, McGregor G, et al. (2012) Determinants of risks: Exposure and vulnerability. In Managing the risks of extreme events and disasters to advance climate change adaptation. A special report of the working Groups I and II of the Intergovernmental Panel on Climate Change, Field CB, et al. (Eds.), Cambridge University Press, Cambrigde and New York, pp: 65108.

19. UNISDR (2015) Global assessment report in disaster risk reduction: 316 .

20. Lavell A, Oppenheimer M, Diop C, Hess J, Lempert R, et al. (2012) Climate change: new dimensions in disaster risk, exposure, vulnerability, and vulnerability, and resilience. In: Managing the Risks of Extreme Events and Disasters to Advance Climate Change Adaptation, Field CB, et al. (Eds.), a Special Report of Working Groups I and II of the Intergovernmental Panel on Climate Change (IPCC). Cambridge University Press, Cambridge, UK, and New York, USA, pp: 25-64.

21. Tsakiris G (2007) Practical application of risk and hazard concepts in proactive planning. European Water 19(20): 47-56.

22. Hewitt K (1983) The idea of calamity in a technocratic age, in: Interpretations of calamity from the viewpoint of human ecology. Hewitt K (Eds..)
Allen and Unwin, Boston, MA and London, UK, pp: 332.

23. Lewis J (1999) Development in Disaster-prone Places: Studies in Vulnerability. IT Publications (Practical Action), London, UK.

24. Bankoff G (2001) Rendring the world safe: vulnerability as western discourse. Disasters 25(10): 19-35.

25. Wisner B, Blaikie P, Cnnon T, Davis I (2004) At risk: Natural hazards, peoples vulnerability, and disasters, $2^{\text {nd }}($ Edn.), Routledge, London, UK.

26. (2011) Handbook of hazards and disaster risk reduction. Wisner B, et al. (Eds.), Routledge, London, UK.

27. ICSU (2008) A science plan for integrated research on disaster risk. Addressing the challenge of natural and human induced environmental hazards. International Council for Science.

28. UNISDR (2009) Global assessment report on disaster risk reduction: Risk and Poverty in a changing climate - invest today for a safer tomorrow. United Nations International Strategy for Disaster Reduction: 207.

29. ICSU-LAC (2009) Understanding and managing risk associated with natural hazards: An integrated Scientific Approach in Latin America and the Caribbean. International Council for Science Regional Office for Latin America and the Caribbean, Rio de Janeiro, Brazil and Mexico City, Mexico.

30. Thieken A, Merz B, Kreibich H, Apel H (2006) Methods for flood risk assessment: Concepts and Challenges. Being a paper presented at the International Workshop on Flash Floods in Urban Areas, Muscat - Sultanate of Oman.

31. Brooks N (2003) Vulnerability, risk and adaptation: A conceptual framework, Tydal Centre fo Climate Change Research, p: 38: 20.

32. Mechler R, Bouwer LM (2015) Understanding trends and projections of disaster losses and climate change: Is vulnerability the missing link? Climate Change 133(1): 23-35.

33. Cutter SL (1996) Vulnerability to environmental hazards. Progress Human Geog 20(4): 529-539. 


\section{Journal of Ecology \& Natural Resources}

34. Pelling M (1999) The political ecology of flood hazard in urban Guyana. Geoforum 30: 249-261.

35. Komendantova N, Patt A, Scolobig A (2014) Understanding risk: The evolution of disaster risk assessment. GFDRR (Global Facility for Disaster Reduction and Recovery).

36. Helgeson JF, Dietz S, Hochrainer-stigler S (2013) Vulnerability to weather disasters: The choice of coping strategies in rural Uganda. Ecology and Society 18 (2): 05390-180202.

37. Seyers P, Li Y, Galloway G, Penning-Rowell E, Shen F, et al. (2013) Flood risk management: A strategic approach. Paris, UNESCO.
38. Lewis J (2009) An island characteristics: Derivative vulnerabilities to indigenous and exogenous hazards, Shima: Inter J Research into Island Cultures 3(1): 315.

39. UNISDR (2011) Global assessment report on disaster risk reduction: Revealing risk, redefining development. United Nations International Strategy for Disaster Reduction: 178.

40. UNISDR (2013) Global assessment report in disaster risk reduction: 288.

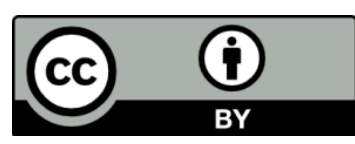

